\title{
A Outra Face do Horário Gratuito: Partidos Políticos e Eleições Proporcionais na Televisão*
}

\author{
Afonso de Albuquerque \\ Fabro Boaz Steibel \\ Carolina Maria Zoccoli Carneiro
}

$\mathrm{E}$ m toda campanha eleitoral, a mesma trama se repete: centenas de candidatos - alguns relativamente famosos; a maioria, ilustres desconhecidos - se acotovelam no Horário Gratuito de Propaganda Eleitoral - HGPE em busca de um lugar ao sol nas campanhas para as eleições proporcionais (para os cargos de vereador, deputado estadual ou deputado federal). Diferentemente do que se passa com o uso do HGPE nas campanhas majoritárias (em especial para o cargo de presidente), o uso da televisão nas campanhas proporcionais tem sido escassamente investigado. Qual é a lógica que preside a distribuição do tempo entre os candidatos? A que interesses ela atende? Que estratégias comunicativas são empregadas? Qual é o impacto efetivo dessas campanhas na decisão do voto?

Quase nada tem sido feito para responder a essas questões. Dentre o pouco que existe sobre o assunto, podemos destacar o artigo "Estratégias de Campanha no Horário Gratuito de Propaganda Eleitoral em Eleições Proporcionais", de Schmitt, Carneiro e Kuschnir (1999). Os autores defendem que o HGPE se apresentaria como um fator de forta-

\footnotetext{
* Uma primeira versão deste artigo foi apresentada no II Congresso da Associação Brasileira de Pesquisadores em Comunicação e Política - Compolítica, realizado em Salvador entre 29 de novembro e $1^{\circ}$ de dezembro de 2007. Agradecemos as críticas e sugestões feitas por Luis Felipe Miguel e Alessandra Aldé, além daquelas apresentadas pelos pareceristas anônimos da DADOS.
}

DADOS - Revista de Ciências Sociais, Rio de Janeiro, Vol. 51, n-2, 2008, pp. 459 a 487. 
lecimento dos partidos políticos, uma vez que permitiria a eles constituir "listas partidárias informais". Bem entendido, isso significa supor três coisas: 1) que os partidos distribuem desigualmente os recursos comunicativos do HGPE (tempo, sobretudo) entre os candidatos; 2) que a propaganda política na televisão tem um impacto eleitoral significativo; 3) e que, por conseguinte, o HGPE permite aos partidos efetivamente favorecer a eleição de alguns candidatos em detrimento de outros.

Tal como os autores, acreditamos que o HGPE se apresenta como um fator de fortalecimento dos partidos políticos, uma vez que faz todos os candidatos dependerem deles para obter acesso ao rádio e à televisão durante as campanhas eleitorais. A sugestão de que isso ocorreria por causa do impacto eleitoral do HGPE, contudo, parece-nos duvidosa, ao menos quando se aplica ao caso das eleições proporcionais. Os autores a sustentam por meio de correlações estatísticas entre o total de votos recebidos pelos candidatos nas eleições de 1994 para deputado federal, no Estado do Rio de Janeiro, e de 1996 para vereador, no município do Rio de Janeiro, e a quantidade de tempo de que eles dispuseram no HGPE. Todavia, a constatação de uma correlação positiva entre os dois fatores não basta para sustentar a interpretação dos autores. Essa correlação significa necessariamente que os candidatos que tiveram mais tempo no HGPE conseguiram, em conseqüência, mais votos; ou, em uma leitura alternativa, que candidatos que, supunha-se, obteriam mais votos foram capazes de conseguir dos partidos mais tempo no HGPE?

Para escapar ao dilema, é preciso recorrer a outros dados, além daqueles apresentados pelos autores. Propomos aqui que a análise da distribuição espacial dos votos dos candidatos pode fornecer pistas importantes para lidar com a questão. Sustentamos que o HGPE só pode ser considerado elemento significativo da explicação da votação de um candidato nos casos em que esta se distribui de modo relativamente homogêneo pelo território no qual se realiza a eleição. Uma alta taxa de concentração dos votos em algumas regiões, em detrimento de outras, constitui uma forte evidência de que outros fatores têm mais influência nos resultados eleitorais do que o HGPE, e que este constitui um elemento menor para explicar a votação de um candidato.

Com base nisso, propomo-nos a analisar a hipótese de que o HGPE representa uma oportunidade de os partidos constituírem listas infor- 
mais entre seus candidatos tendo em vista dois aspectos: 1) a premissa de sua eficácia como instrumento de comunicação política no âmbito das eleições proporcionais, de tal modo que uma maior quantidade de tempo oferecido aos candidatos deveria resultar na conquista de mais votos por eles; 2) a análise das estratégias utilizadas pelos partidos, considerando a distribuição do tempo no HGPE entre os candidatos. Interessa-nos, em particular, investigar se tal distribuição segue uma lógica fundamentalmente eleitoral (a maximização dos votos para o próprio partido ou a hierarquização das chances de cada candidato de ganhar as eleições) ou se obedece a outro(s) princípio(s). Para tal, examinamos os dados relativos à eleição de 2004 para o cargo de vereador no município do Rio de Janeiro. Antes, contudo, devemos considerar algumas questões mais gerais, relativas ao relacionamento entre candidatos proporcionais e partidos políticos no Brasil, tendo em vista as características do sistema eleitoral brasileiro e do modelo de propaganda política na televisão vigente no país.

\section{PARTIDOS, CANDIDATOS E PROPAGANDA NA TELEVISÃO}

A análise do impacto eleitoral da propaganda política na televisão sobre as eleições proporcionais, bem como das estratégias utilizadas pelos partidos políticos em relação à divisão dos recursos para a propaganda política no meio televisivo (tempo, sobretudo) entre os candidatos, apresenta desafios particularmente complexos no Brasil, dadas as características particulares de seus sistemas partidário, eleitoral e de seu modelo de propaganda política na televisão. Trata-se, em especial, de considerar criticamente três argumentos bastante difundidos que incidem sobre o nosso tema:

1) que o sistema partidário brasileiro é frágil, estruturado em torno de partidos pouco representativos e cuja identidade ideológica é pouco definida;

2) que as características do sistema eleitoral brasileiro conspiram contra a coesão dos partidos políticos, uma vez que fomentam a disputa intrapartidária entre os candidatos às eleições proporcionais;

3) que a crescente centralidade dos meios de comunicação eletrônicos (de modo particular, a televisão) tem favorecido um novo estilo de fazer política, bastante centrado na personalidade dos políticos, em detrimento dos partidos políticos. 


\section{FRAGILIDADE DOS PARTIDOS POLÍTICOS BRASILEIROS}

É bastante difundido, tanto no meio acadêmico quanto entre o público leigo, o argumento de que o Brasil apresenta um sistema partidário frágil, estruturado em torno de partidos insuficientemente coesos, indisciplinados, ideologicamente inconsistentes e pouco representativos em relação aos interesses da sociedade. Não cabe, dentro da proposta deste artigo, avaliar esse argumento em detalhes, mas sublinhar algumas formas pelas quais ele afeta o nosso objeto de investigação. Em especial, cabe destacar o caráter fortemente normativo que assumem algumas versões do argumento, bem como apontar alguns limites que se apresentam para a análise a partir daí.

Um exemplo particularmente expressivo de crítica dos partidos políticos brasileiros a partir de um viés fortemente normativo é fornecido pela análise que Mainwaring (2001) faz acerca deles. Segundo esse autor, os partidos catch-all brasileiros "1 "são fracos; oficialmente seus organismos internos dispõem de amplos poderes, mas na prática são pobres em recursos e pessoal; têm pouca função em campanhas eleitorais, fraca presença no Congresso, raramente se reúnem e são pouco profissionalizados" (ibidem:180). O autor sugere que tais características se explicam fundamentalmente pelo individualismo dos políticos brasileiros e pelas lutas internas que se travam nos partidos ${ }^{2}$. Em termos mais amplos, caracteriza os arranjos institucionais brasileiros como particularmente hostis à manutenção de um governo democrático, uma vez que combina "partidos fracos, um sistema partidário frouxamente institucionalizado, um sistema partidário altamente fragmentado, que é polarizado no âmbito das elites, e presidencialismo" (1995:392).

O diagnóstico e o prognóstico apresentados por Mainwaring sobre o sistema partidário, os partidos políticos e a democracia no Brasil têm sido matizados por outros autores. Em alguns casos, eles dão conta de um quadro menos severo do que aquele apresentado por esse autor. Carreirão e Kinzo (2004), por exemplo, indicam que, entre 1989 e 2002, a proporção de eleitores com preferência partidária oscilou em torno de $40 \%$ e $50 \%$ do total, o que, por certo, não é uma cifra das mais notáveis, mas tampouco é insignificante. Além disso, as taxas de identificação partidária dos principais partidos teriam conservado uma expressiva estabilidade ao longo do período. Do mesmo modo, diversos autores têm dado conta de que os partidos brasileiros apresentam um nível considerável de disciplina nas votações no plenário, bastante su- 
perior àquele suposto pela afirmação de Mainwaring (Santos, 2002; Pereira e Mueller, 2003). Nicolau (1996) contesta a proposição de que o alto nível de fragmentação partidária que caracteriza a situação brasileira implique necessariamente uma ameaça à democracia.

Para além do conteúdo específico das afirmações de Mainwaring, fazse necessário considerar com a devida cautela alguns dos pressupostos que orientam sua análise. Chama a atenção, em particular, o fato de os modelos teóricos utilizados pelo autor para tratar dos partidos e do sistema partidário brasileiros terem sido desenvolvidos fundamentalmente para dar conta da realidade dos países da Europa Ocidental (Montero e Gunther, 2002) e apresentar um forte caráter normativo (Daalder, 2002). Resulta daí que a análise julga o sistema partidário brasileiro pelo que ele não poderia ser, dadas as circunstâncias particulares de seu desenvolvimento histórico e, desse modo, deixa de considerá-lo efetivamente pelo que ele é.

\section{Sistema Eleitoral e Sistema Partidário}

Tem sido bastante recorrente a idéia de que o sistema eleitoral brasileiro constitui um elemento fundamental para explicar a fragilidade do sistema partidário brasileiro. Dois aspectos, em especial, têm sido destacados a esse respeito: o sistema de representação proporcional com listas abertas e a adoção de distritos multinominais, alguns de grande magnitude.

O sistema de representação proporcional tem como objetivo garantir a maior correspondência possível entre a proporção de votos recebidos por um partido e a quantidade de cadeiras a que ele terá direito no Parlamento. Na maior parte dos países que adotam sistemas de representação proporcional, a eleição opera por meio de um sistema de listas fechadas, no qual os votos dos eleitores determinam o número de vagas a que cada partido tem direito, mas cabe aos partidos, e não aos eleitores, determinar quem irá ocupá-las. No sistema brasileiro de listas abertas, o eleitor pode votar diretamente no candidato (ou, alternativamente, na legenda), e os candidatos eleitos são aqueles que obtêm mais votos dentro do próprio partido, dentro do número de vagas conquistadas por este (Ames, 2003). Tais normas estimulariam um comportamento eleitoral individualista tanto por parte dos eleitores quanto dos candidatos. Os eleitores seriam estimulados a um voto personalista nos candidatos, independentemente de seu partido. Os candidatos, por sua 
vez, seriam forçados a disputar as cadeiras em jogo não apenas com os candidatos dos partidos adversários mas também com os do próprio partido (ibidem; Mainwaring, 1995; 2001).

Essas tendências individualistas seriam reforçadas pela magnitude dos distritos eleitorais brasileiros - que, no caso das eleições para a Câmara dos Deputados, variam entre 8 e 70 representantes; no caso das Assembléias Legislativas estaduais, entre 24 e 94 representantes. Em tais circunstâncias, o vínculo entre os eleitores e seus representantes se torna mais frágil e, ao mesmo tempo, o nível de competição entre os candidatos de um mesmo partido se torna maior.

É preciso alguma cautela para evitar tomar esse argumento de maneira demasiado determinista. Dizer que as regras do jogo estimulam um comportamento individualista por parte dos candidatos e eleitores não é o mesmo que afirmar que tais agentes políticos necessariamente ajam dessa forma. Samuels (1997), por exemplo, sugere que o $\mathrm{PT}^{*}$ foi capaz de institucionalizar sua legenda de modo bastante eficiente e forjar laços sólidos entre seus representantes eleitos e entre estes e seus eleitores. Em particular, o partido fez do voto de legenda um instrumento central de sua estratégia eleitoral. Isso não quer dizer, é claro, que não exista uma disputa interna entre os candidatos de um mesmo partido. Essa disputa de fato ocorre em virtude do número determinado de candidatos eleitos. O que queremos mostrar é que a afirmação de que a disputa intrapartidária enfraquece o partido como ator político e como uma unidade institucional é simplista, não devendo ser tomada como verdade sem uma prévia avaliação caso a caso.

\section{Mídia Eletrônica e Partidos Políticos}

Finalmente, tem sido freqüentemente sugerido que o papel central dos meios de comunicação eletrônicos na vida política atual é inversamente proporcional à importância dos partidos políticos. No limite, esse argumento aponta para a direção de uma substituição dos partidos pelos meios de comunicação no tocante a algumas funções clássicas da vida política, particularmente à intermediação do contato entre os cidadãos e seus representantes no governo, e entre os candidatos e eleitores nas campanhas eleitorais. Essa situação foi descrita, em diferentes termos,

\footnotetext{
* Ver lista de siglas dos partidos políticos, com os respectivos significados, no final deste artigo.
} 
como a emergência de uma democracia de público no lugar de uma democracia de partidos (Manin, 1995) ou como o advento de uma política centrada no candidato (Wattenberg, 1991).

Tais circunstâncias proveriam um terreno fértil para o desenvolvimento de formas individualistas de ação política, baseadas na construção de imagens para consumo público, produzidas com o auxílio de consultores profissionais, em detrimento de formas coletivistas de atuação, sustentadas pela ação concreta das bases partidárias e pelo compromisso efetivo dos partidos com doutrinas políticas e/ou plataformas eleitorais específicas. Esse processo verificar-se-ia de forma particularmente intensa no Brasil não apenas em função da fragilidade histórica dos partidos brasileiros mas também em função das características fortemente media centric da sociedade brasileira, bastante dependente da televisão (Lima, 1994).

Aqui também se faz necessária uma boa dose de cautela. Em primeiro lugar, quando considerado mais detidamente, o argumento da substituição é bem menos convincente do que parece à primeira vista. Mais do que descrever uma transformação efetiva da forma de fazer política em alguma parte do mundo, ele reflete uma mudança no foco privilegiado da análise, o qual se deslocou dos países da Europa Ocidental (paradigmáticos do ponto de vista dos estudos sobre os partidos políticos) para os Estados Unidos (o modelo por excelência da profissionalização da atividade política). Além disso, ao enfocar a substituição de partidos pelos meios de comunicação de massa, impede a análise sobre os modos como eles coexistem no tempo (Albuquerque, 2005).

Especificamente no que diz respeito ao caso brasileiro, parece plausível que, pelo menos sob alguns aspectos, o uso dos meios de comunicação eletrônicos se converta em um fator de fortalecimento dos partidos políticos, e não o contrário. Isso é particularmente verdadeiro em relação à propaganda política na televisão. Afinal, é aos partidos, e não aos candidatos tomados individualmente, que a legislação eleitoral brasileira concede tempo gratuito na televisão. Desse modo, os partidos se convertem em mediadores indispensáveis do acesso dos candidatos à televisão. Resta saber quais são as conseqüências concretas disso dos pontos de vista das campanhas eleitorais e dos partidos políticos. Trata-se, em particular, de averiguar a pertinência do argumento de Schmitt, Carneiro e Kuschnir (1999) sobre o uso do HGPE como recurso para a construção de uma lista partidária informal. 


\section{Metodologia}

Nossa análise tem por objeto o uso da propaganda política na televisão na campanha eleitoral de 2004 para vereador no município do Rio de Janeiro. Nessa ocasião, 1.110 candidatos, de 27 partidos, disputaram as 50 vagas disponíveis para a Câmara de Vereadores local. A opção pela análise de uma eleição de âmbito municipal se fez em nome da simplicidade: o município fornece um distrito menor e mais coeso do que aquele que serve de base às eleições estaduais e federais (em ambos os casos as unidades federativas servem como distritos). A escolha da eleição de 2004 se justifica não apenas por se tratar do pleito mais recente mas também pela grande disponibilidade de dados sobre o pleito, tanto no que diz respeito à votação - o Tribunal Superior Eleitoral - TSE divulgou, em seu site, dados relativos à votação dos candidatos em cada uma das zonas eleitorais - quanto ao material veiculado no HGPE na televisão - gentilmente cedido pelo Laboratório de Pesquisas em Comunicação Política e Opinião Pública - Doxa/Instituto Universitário de Pesquisas do Rio de Janeiro - Iuperj.

A análise empírica realizada neste artigo tem por objetivo coletar e relacionar três tipos de dados, relativos a: 1) a distribuição espacial dos votos dos candidatos no município; 2) a correlação entre a quantidade de votos obtidos pelos candidatos e a distribuição do tempo no HGPE, independentemente do partido político dos candidatos; 3) a distribuição do tempo no HGPE entre os candidatos de um mesmo partido e sua ordem de votação no interior do partido.

A análise da distribuição espacial da votação dos candidatos visa verificar o equilíbrio dos votos dos candidatos em diferentes regiões do município. As unidades de análise adotadas foram as subprefeituras em que a cidade foi dividida em 1993. As dez subprefeituras então existentes eram as seguintes: 1) Centro; 2) Zona Sul;3) Zona Norte;4) Grande Méier; 5) Leopoldina; 6) Ilha do Governador; 7) Central; 8) Barra da Tijuca; 9) Bangu; 10) Campo Grande. Como regra geral, verificou-se uma expressiva correspondência entre as áreas compreendidas pelas subprefeituras e pelas zonas eleitorais. Apenas 8 de um total de 96 zonas eleitorais abrangiam bairros pertencentes a diferentes subprefeituras. Nesses casos, procurou-se identificar, com base na lista dos locais de votação, qual a subprefeitura dominante na composição de cada zona eleitoral. 
Pudemos, assim, elaborar um quadro aproximado do peso relativo de cada subprefeitura no eleitorado do município. Centro e Ilha do Governador são as subprefeituras que apresentam menor número de eleitores (cada uma delas corresponde a aproximadamente $4 \%$ do eleitorado do município), enquanto a subprefeitura Central apresenta a maior quantidade de eleitores (cerca de 18\%). As demais subprefeituras correspondem a algo entre 7\% e 13\% do total de eleitores (Figura 1). Embora tais cifras estejam longe de configurar uma distribuição equilibrada, pode-se dizer, ao menos, que são da mesma escala de magnitude. A criação de novas subprefeituras - tais como a do Complexo do Alemão, Complexo da Maré, a subdivisão da Zona Sul - mudou esse quadro e levou a que o vínculo entre as subprefeituras e as zonas eleitorais se tornasse mais frágil; daí a opção pelas subprefeituras originais.

Em uma situação de perfeito equilíbrio, a proporção dos votos obtidos por um candidato em cada subprefeitura seria idêntica ao peso desta no eleitorado do município; desse modo, ele obteria $4,1 \%$ de seus votos no Centro; $12,4 \%$ na Zona Sul; $7,1 \%$ na Zona Norte etc. Contudo, seria

Figura 1

Porcentagem dos Votos do Município a que Corresponde Cada Subprefeitura

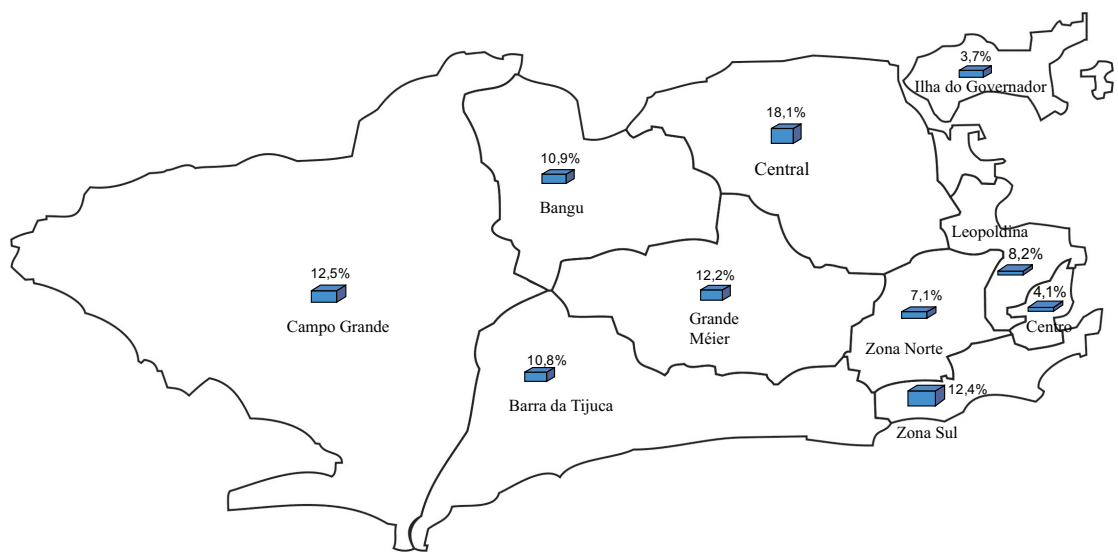

\begin{tabular}{|l|c|c|c|c|c|c|c|c|c|c|c|}
\hline Subprefeitura & Centro & $\begin{array}{c}\text { Zona } \\
\text { Sul }\end{array}$ & $\begin{array}{c}\text { Zona } \\
\text { Norte }\end{array}$ & $\begin{array}{c}\text { Grande } \\
\text { Méier }\end{array}$ & $\begin{array}{c}\text { Leo- } \\
\text { poldi- } \\
\text { na }\end{array}$ & $\begin{array}{c}\text { Ilha do } \\
\text { Gover- } \\
\text { nador }\end{array}$ & $\begin{array}{c}\text { Cen- } \\
\text { tral }\end{array}$ & $\begin{array}{c}\text { Barra } \\
\text { da } \\
\text { Tijuca }\end{array}$ & $\begin{array}{c}\text { Bangu } \\
\text { Campo } \\
\text { Gran- } \\
\text { de }\end{array}$ & Total \\
\hline $\begin{array}{l}\text { Distribuição da } \\
\text { carteira }\end{array}$ & 4,1 & 12,4 & 7,1 & 12,2 & 8,2 & 3,7 & 18,1 & 10,8 & 10,9 & 12,5 & 100,0 \\
\hline
\end{tabular}

Fonte: TSE. 
pouco sensato esperar que, em uma situação real, o perfil de votação dos candidatos refletisse exatamente esses valores. Assim, temos de trabalhar com critérios aproximados na análise do equilíbrio da distribuição de votos dos candidatos. Definir parâmetros de aproximação, nesses termos, é necessariamente definir padrões ideais de equilíbrio. Dado que não se referem ao mundo real, mas a condições ideais, tais parâmetros são necessariamente arbitrários. Assim, e em nome da simplicidade, consideramos a votação de uma subprefeitura relativamente equilibrada quando ela se situa no intervalo entre a metade e o dobro de seu peso no eleitorado total do município. Desse modo, por exemplo, um candidato terá uma votação relativamente equilibrada na Zona Sul quando a proporção de votos obtida por ele nessa subprefeitura corresponder a algo entre $6,2 \%$ e $24,8 \%$ do total de votos obtido por ele.

Esses dados dizem respeito a uma medida de equilíbrio relativa a cada subprefeitura, tomada individualmente. Nossa análise, por outro lado, diz respeito à distribuição dos votos de um candidato ao longo de todo o município, isto é, por meio de todo o conjunto das subprefeituras. Assim, estabelecemos três faixas de distribuição dos votos, às quais denominamos votação equilibrada, votação desequilibrada e votação concentrada. A votação equilibrada se caracteriza quando, em até duas subprefeituras, a votação de um candidato se situa fora das margens que definem o equilíbrio. Quando isso acontece entre três e cinco subprefeituras, o perfil de votação do candidato se caracteriza como desequilibrado; quando ocorre em mais de cinco subprefeituras, como concentrado. Acreditamos que uma forte influência do HGPE na votação de um candidato é bastante plausível quando se tem uma distribuição equilibrada dos votos, menos provável no caso de votação desequilibrada e bastante improvável em votação concentrada.

Obviamente, a análise da distribuição dos votos não dá conta de tudo. É bem verdade que ela permite, com alguma segurança, afastar a possibilidade de que um candidato com perfil de votação concentrado seja eleito primordialmente sob influência do HGPE. Contudo, o mesmo não ocorre com o caso inverso. Um perfil de votação equilibrado não é necessariamente um produto da influência do HGPE. Para que tal inferência possa ser levantada, é preciso que exista uma correlação significativa entre a quantidade de votos obtida por um candidato e a exposição do candidato no HGPE. 
Essa exposição foi classificada tendo em vista seu tempo médio por programa. Para fins de análise, distinguimos cinco níveis de exposição: uma exposição forte é caracterizada por uma exposição média de 20 segundos ou mais por programa; a exposição média é situada no intervalo compreendido entre 10 e 20 segundos; a pequena exposição se situa entre 5 e 10 segundos médios por programa; e abaixo disso teríamos uma exposição inexpressiva. O quinto nível é constituído pelos candidatos que não tiveram acesso ao HGPE.

A hipótese de uma influência significativa do HGPE na votação dos candidatos seria favorecida caso ficasse comprovado que os candidatos mais votados das eleições tivessem, tendencialmente, maior exposição no HGPE. Ainda assim, tais dados não seriam conclusivos: seria necessário cotejá-los com a distribuição espacial dos votos. Dessa forma, uma forte evidência de influência significativa do HGPE somente aconteceria no caso de candidatos cuja votação expressiva coincidisse com um nível significativo de exposição no HGPE, na forma do tempo médio ou da freqüência e cujo perfil de distribuição de votos no município fosse relativamente equilibrado.

O terceiro conjunto de dados tem por objeto a correlação entre a votação dos candidatos e o grau de sua exposição no HGPE, considerado de uma perspectiva intrapartidária. Os parâmetros de avaliação são os mesmos utilizados no item anterior, mas sua ordenação leva em conta as listas de candidatos de cada partido em particular, e não do conjunto dos candidatos. Os partidos escolhidos para análise foram os seguintes: PFL, PSDB, PT, PMDB, PL, PP, PTB, PPS e PDT.

\section{Distribuição dos Votos}

A análise da distribuição dos votos dos candidatos no município permitiu identificar exemplos dos três padrões de distribuição de voto a que nos referimos anteriormente. Um exemplo extremo do perfil concentrado é oferecido pela votação do candidato Jorge Pereira, do PT do B. Entre as dez subprefeituras, sua votação ficou fora dos parâmetros que definem o equilíbrio para a nossa análise em nove. De fato, 83,4\% dos votos obtidos pelo candidato foram conquistados na subprefeitura da Ilha do Governador. Esse é o maior percentual de concentração de votos em uma única subprefeitura entre todos os vereadores eleitos. É bem verdade que um número considerável de outros candidatos atingiu índices de concentração próximos aos de Jorge Pereira. A candida- 
ta Lucinha, do PSDB, por exemplo, obteve $80,6 \%$ de seus votos na subprefeitura de Campo Grande; Nadinho de Rio das Pedras conquistou 76,7\% de seus votos na subprefeitura da Barra da Tijuca; e Leila do Flamengo obteve $81,9 \%$ de seus votos na Zona Sul ${ }^{3}$. De fato, entre os 50 vereadores eleitos, 14 conquistaram pelo menos dois terços de seus votos na região correspondente a uma única subprefeitura. O que mais chama a atenção, no caso de Jorge Pereira, é que sua votação é fortemente concentrada em uma das subprefeituras com menor número de eleitores (aproximadamente $4 \%$ do eleitorado do município). Dito de outro modo, o peso da subprefeitura da Ilha do Governador é 22,9 vezes maior no perfil de votação do candidato do que no município do Rio de Janeiro. Por outro lado, sua votação é quase nula em um grande número de subprefeituras.

A votação da vereadora Liliam Sá (PL) fornece um exemplo de votação desequilibrada. Em quatro subprefeituras, sua votação ficou fora dos parâmetros que definem o equilíbrio. Em um caso, isso acontece para cima: a Zona Sul, com cerca de $12 \%$ dos eleitores, respondeu a $46 \%$ dos votos da candidata. Isso significa que o peso da subprefeitura na cartela de votação da candidata corresponde aproximadamente ao triplo do que a subprefeitura tem no município. Nos outros três casos, a votação

Tabela 1

Porcentagem dos Votos Obtidos pelo Candidato Jorge Pereira em cada Subprefeitura

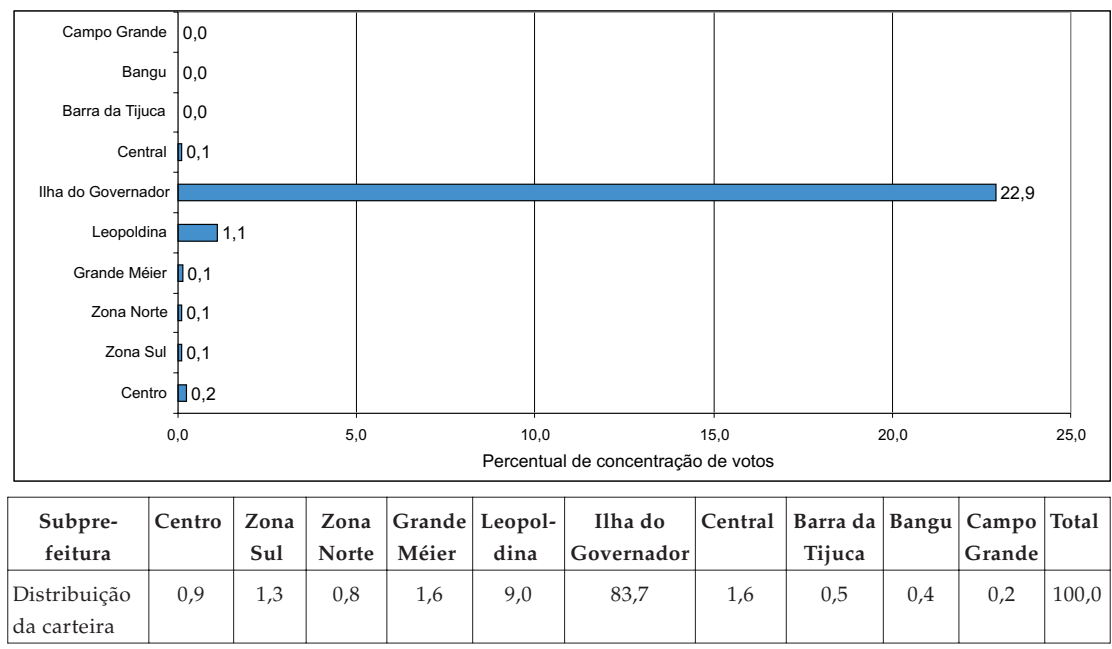

Fonte: TSE. 
Tabela 2

Porcentagem dos Votos Obtidos pela Candidata Liliam Sá em cada Subprefeitura

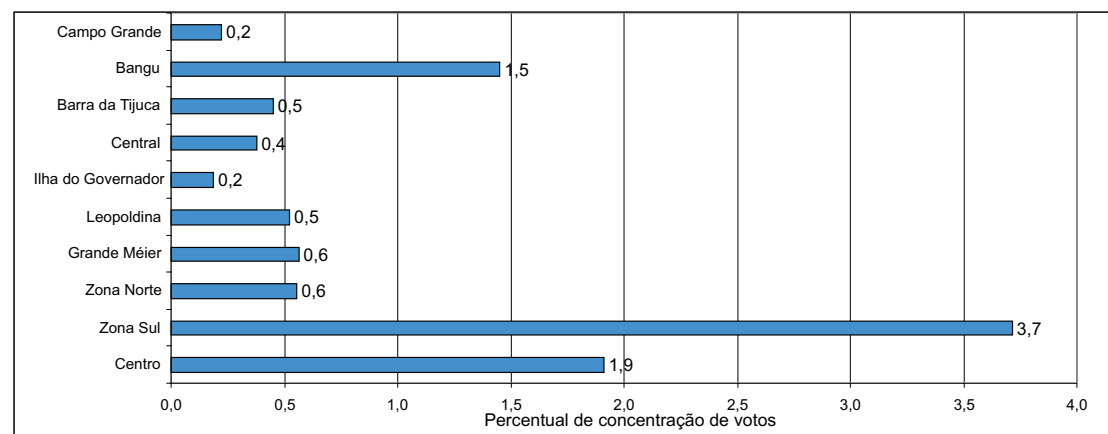

\begin{tabular}{|l|c|c|c|c|c|c|c|c|c|c|c|}
\hline \multicolumn{1}{|c|}{ Subprefeitura } & $\begin{array}{c}\text { Cen- } \\
\text { tro }\end{array}$ & $\begin{array}{c}\text { Zona } \\
\text { Sul }\end{array}$ & $\begin{array}{c}\text { Zona } \\
\text { Norte }\end{array}$ & $\begin{array}{c}\text { Grande } \\
\text { Méier }\end{array}$ & $\begin{array}{c}\text { Leopol- } \\
\text { dina }\end{array}$ & $\begin{array}{c}\text { Ilha do } \\
\text { Gover- } \\
\text { nador }\end{array}$ & $\begin{array}{c}\text { Central } \\
\text { Barra } \\
\text { da } \\
\text { Tijuca }\end{array}$ & Bangu & $\begin{array}{c}\text { Campo } \\
\text { Grande }\end{array}$ & Total \\
\hline $\begin{array}{l}\text { Distribuição da } \\
\text { carteira }\end{array}$ & 7,8 & 46,0 & 3,9 & 6,9 & 4,3 & 0,7 & 6,8 & 4,9 & 15,9 & 2,8 & 100,0 \\
\hline
\end{tabular}

Fonte: TSE.

foi inferior aos parâmetros mínimos do equilíbrio: na região Central, a votação da candidata correspondeu a cerca de $40 \%$ do peso da subprefeitura no eleitorado do município; na Ilha do Governador e em Campo Grande, esse índice foi de aproximadamente $20 \%$ (Tabela 2).

Finalmente, Édson Santos, do PT, apresenta um caso de votação equilibrada. Sua votação ficou dentro da faixa de equilíbrio em nove das dez subprefeituras. A subprefeitura de maior peso relativo na cartela de votação do candidato é o Centro, com pouco mais de $6 \%$ de seus votos: ele é cerca de $60 \%$ superior ao peso da subprefeitura no eleitorado do município. A única subprefeitura na qual a votação do candidato escapou aos parâmetros que definem uma votação equilibrada foi Campo Grande. O candidato obteve aí 4,9\% de seus votos totais, o que configura um índice relativo de $40 \%$ em relação à participação da subprefeitura no eleitorado (Tabela 3).

A análise da distribuição dos votos dos candidatos pelo município indica uma predominância de um perfil de votação concentrado entre os candidatos a vereador do Rio de Janeiro. Esse perfil corresponde a 28 entre os 50 vereadores eleitos ( $56 \%$ do total). Outros 14 vereadores (28\%) tiveram um perfil de votação desequilibrado e 8 apresentaram um perfil equilibrado (16\%). 
Tabela 3

Porcentagem dos Votos Obtidos pelo Candidato Édson Santos em cada Subprefeitura

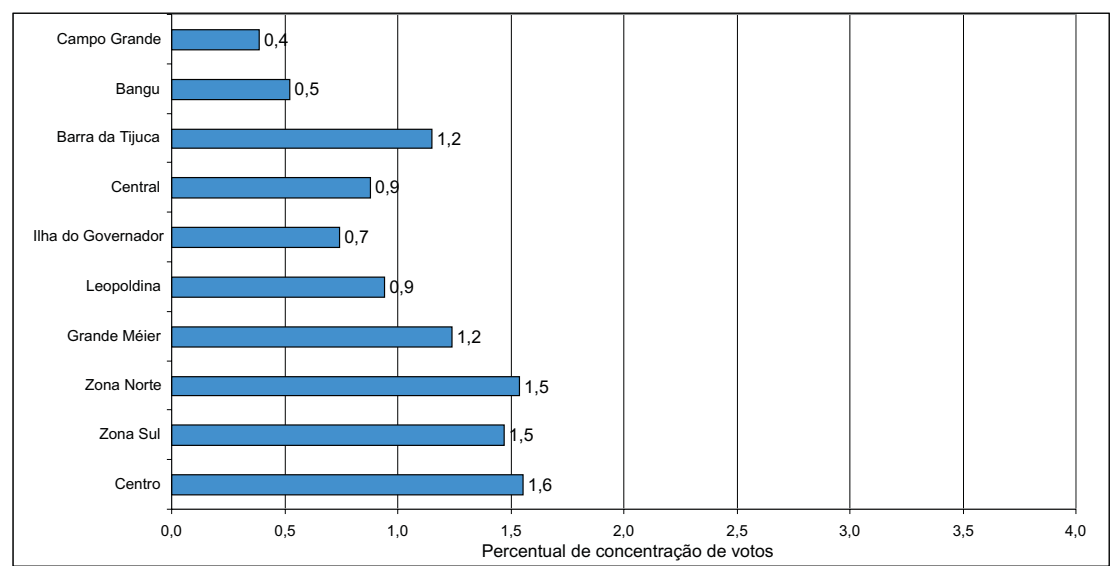

\begin{tabular}{|l|c|c|c|c|c|c|c|c|c|c|c|}
\hline Subprefeitura & Centro & $\begin{array}{c}\text { Zona } \\
\text { Sul }\end{array}$ & $\begin{array}{c}\text { Zona } \\
\text { Norte }\end{array}$ & $\begin{array}{c}\text { Grande } \\
\text { Méier }\end{array}$ & $\begin{array}{c}\text { Leopol- } \\
\text { dina }\end{array}$ & $\begin{array}{c}\text { Ilha do } \\
\text { Gover- } \\
\text { nador }\end{array}$ & $\begin{array}{c}\text { Central } \\
\text { Barra } \\
\text { da } \\
\text { Tijuca }\end{array}$ & Bangu & $\begin{array}{c}\text { Campo } \\
\text { Grande }\end{array}$ & Total \\
\hline $\begin{array}{l}\text { Distribuição } \\
\text { da carteira }\end{array}$ & 6,3 & 18,2 & 10,9 & 15,1 & 7,8 & 2,7 & 16,0 & 12,5 & 5,7 & 4,9 & 100,0 \\
\hline
\end{tabular}

Fonte: TSE.

Entre os vereadores mais votados, o perfil de concentração de votos é ainda mais pronunciado do que entre o conjunto dos eleitos. Dos 10 vereadores mais votados, 7 tiveram uma votação concentrada; 2 , uma votação desequilibrada; e apenas 1 teve um perfil equilibrado. Essas proporções se mantiveram praticamente constantes no conjunto dos 20 mais votados: 13 tiveram votação concentrada, 4 desequilibrada e 3 equilibrada.

Em seu conjunto, os dados relativos ao perfil de distribuição dos votos dos candidatos indicam que, como regra geral, o HGPE não desempenhou um papel de relevo na obtenção de votos pelos candidatos a vereador do Rio de Janeiro. O alto índice de concentração dos votos dos candidatos eleitos (e particularmente dos mais votados entre eles) indica que o esforço de campanha tradicional permanece muito mais importante para a eleição dos vereadores do que o uso da televisão. 


\section{EXPOSIÇÃO DOS CANDIDATOS NO HGPE}

O segundo conjunto de evidências analisadas aqui se refere ao cruzamento dos dados relativos à quantidade de tempo a que cada candidato teve direito no HGPE e a quantidade de votos obtida por ele nas urnas.

À primeira vista, elas parecem sugerir um vínculo significativo entre os dois tipos de dados. Entre os 1.110 candidatos que concorreram às eleições, 980 obtiveram algum tempo na televisão, e 130 não. Todos os 50 vereadores eleitos obtiveram tempo na televisão. Entre os 50 candidatos que obtiveram maior tempo na televisão, metade foi eleita. A proporção de eleitos subiu para $60 \%$ entre os 20 candidatos que obtiveram mais tempo na televisão. Entre os 10 candidatos com mais tempo na televisão, nada menos do que 8 foram eleitos. Seriam tais dados uma evidência da eficácia eleitoral do HGPE?

É preciso cautela antes de subscrever tal interpretação. Para começar, as regras eleitorais brasileiras tornam possível que a lista dos candidatos eleitos apresente divergências importantes em relação à dos candidatos mais votados. As vagas na Câmara são distribuídas em primeiro lugar para os partidos (ou para as coalizões de partidos), tendo em vista o somatório de todos os votos atribuídos a seus candidatos e à(s) legenda(s). Para obter sua vaga, é necessário primeiro que um partido atinja o coeficiente eleitoral. Caso isso não aconteça, o candidato não será eleito, mesmo que sua votação individual seja significativa. Cyro Garcia, por exemplo, obteve a qüinquagésima maior votação individual entre os candidatos a vereadores, com 16.122 votos, mas não foi eleito porque seu partido falhou em obter o coeficiente eleitoral. No extremo oposto, a candidata Senhorita Suely foi eleita apesar de ter obtido apenas 6.827 votos, impulsionada pelo grande número de votos de legenda recebidos por seu partido, o Prona.

O caso de Senhorita Suely ilustra ainda um segundo problema. É tremendamente difícil avaliar o impacto do HGPE no que concerne ao voto de legenda. De fato, ela foi a candidata que obteve, com folga, a maior quantidade de tempo na televisão: 1.407 segundos no total, em uma média de 40,2 segundos por programa (o segundo candidato com mais tempo na televisão foi Fernando Gusmão, do PC do B, que obteve 1.048 segundos no total). O resultado das eleições, porém, indica que, se o HGPE teve algum impacto positivo na eleição de Senhorita Suely, este se deu antes por vias indiretas (voto de legenda) do que pelo apoio direto a seu nome. 
Um terceiro problema que a justaposição das listas de vereadores eleitos e de candidatos contemplados com mais tempo no HGPE esconde se refere à significância da diferença entre a quantidade de tempo obtida pelos diversos candidatos. É muito fácil apontar que alguns candidatos obtiveram mais tempo do que seus adversários; porém, o quanto essa diferença é significativa? Ter mais tempo significa ter tempo suficiente para ser notado pelo público? Aparecer na televisão significa necessariamente obter algum tipo de destaque?

A princípio, as condições gerais da campanha no HGPE não parecem particularmente favoráveis para que um candidato se destaque: afinal, nada menos do que 976 candidatos obtiveram algum acesso à televisão durante a campanha. Desses, 9 obtiveram uma média superior a 20 segundos por programa; 12 obtiveram entre 10 e 20 segundos (seriam 13 candidatos, caso incluíssemos Didier Pereira, do PCO, mas decidimos excluí-lo do cálculo diante do fato de o registro de sua candidatura ter sido negado); e 65 obtiveram entre 5 e 10 segundos. Os demais 890 candidatos contaram com menos de 5 segundos por programa. Para fins práticos, consideramos o primeiro grupo de candidatos como tendo grande destaque no HGPE; o segundo, um médio destaque; o terceiro, um pequeno destaque; e o quarto, nenhum destaque. A Tabela 4 contempla os candidatos com grande destaque no HGPE, e a Tabela 5 os candidatos com médio destaque.

Tabela 4

Candidatos com Grande Destaque no HGPE

\begin{tabular}{|c|c|c|c|c|}
\hline Candidato & Partido & Tempo Médio & Votação & Resultado \\
\hline Senhorita Suely & Prona & $40,2 \mathrm{~s}$ & 6.827 & Eleita em $50^{\circ}$ \\
\hline Fernando Gusmão & PC do B & $29,9 \mathrm{~s}$ & 36.434 & Eleito em $8^{\underline{o}}$ \\
\hline Cristiane Brasil & РTB & $29,9 \mathrm{~s}$ & 13.315 & Eleita em $45^{\circ}$ \\
\hline Lucinha & PSDB & $27,9 \mathrm{~s}$ & 67.073 & Eleita em $2^{\circ}$ \\
\hline Édson Santos & PT & $25,3 \mathrm{~s}$ & 44.585 & Eleito em $4^{\circ}$ \\
\hline Luiz Carlos Ramos & PSDB & $22,5 \mathrm{~s}$ & 24.102 & Eleito em $22^{\circ}$ \\
\hline Luiz Antônio Guaraná & PSDB & $21,9 \mathrm{~s}$ & 21.009 & Eleito em $32^{\circ}$ \\
\hline Cyro Garcia & PSTU & $21,8 \mathrm{~s}$ & 16.122 & Não-eleito [60ㅜ \\
\hline Ricardo Maranhão & PSB & $20,5 \mathrm{~s}$ & 9.005 & Não-eleito [ $86^{\circ}$ ] \\
\hline
\end{tabular}

Fontes: TSE e HGPE - município do Rio de Janeiro (2004). 
A Outra Face do Horário Gratuito: Partidos Políticos...

Tabela 5

Candidatos com Médio Destaque no HGPE

\begin{tabular}{|c|c|c|c|c|}
\hline Candidato & Partido & Tempo Médio & Votação & Resultado \\
\hline Brizola Neto & PDT & $16,7 \mathrm{~s}$ & 24.198 & Eleito em $21^{\circ}$ \\
\hline Eliomar Coelho & $\mathrm{PT}$ & $14,9 \mathrm{~s}$ & 18.296 & Eleito em $37^{\circ}$ \\
\hline Adilson Pires & PT & $14,7 \mathrm{~s}$ & 9.995 & Não-eleito [79$]$ \\
\hline Edimilson Dias & $\mathrm{PT}$ & $13,9 \mathrm{~s}$ & 9.023 & Não-eleito [85ำ \\
\hline Jorge Babu & $\mathrm{PT}$ & $13,7 \mathrm{~s}$ & 24.532 & Eleito em $19^{\circ}$ \\
\hline Eliane Cunha & PRP & $13,5 \mathrm{~s}$ & 248 & Não-eleita [858ํㅜ \\
\hline Pedro Porfírio & PDT & $12,4 \mathrm{~s}$ & 13.924 & Não-eleito [65ำ \\
\hline Eraldo Macedo & PRP & $12,0 \mathrm{~s}$ & 10.083 & Não-eleito [78] \\
\hline Liliam Sá & PL & $11,1 \mathrm{~s}$ & 24.282 & Eleita em $20^{\circ}$ \\
\hline Jorge Pereira & PT do B & $10,3 \mathrm{~s}$ & 44.497 & Eleito em $5^{\circ}$ \\
\hline Wilson Leite Passos & $\mathrm{PP}$ & $10,3 \mathrm{~s}$ & 8.078 & Não-eleito [95ำ \\
\hline Lourival Casula & $\mathrm{PT}$ & $10,0 \mathrm{~s}$ & 9.035 & Não-eleito [84ํㅜ \\
\hline
\end{tabular}

Fontes: TSE e HGPE - município do Rio de Janeiro (2004).

Em análise das eleições proporcionais de 1994 e 1996, Schmitt, Carneiro e Kuschnir (1999) constataram, respectivamente, uma correlação da ordem de 0,53 e 0,50 entre a quantidade de votos obtida por candidato e o tempo com que cada um contou no HGPE. A aplicação do coeficiente de Pearson ao conjunto dos candidatos que concorreram à eleição de 2004 resultou em uma correlação da ordem de 0,61 ( $\mathrm{n}=1.100)$ ainda mais expressiva do que aquela encontrada pelos autores. Contudo, devemos considerar esse índice com alguma cautela em face da natureza de nossa amostra. Dos 1.100 candidatos que concorreram às eleições, cerca de $92 \%$ se situam na faixa de "nenhum destaque" ou não obtiveram tempo algum na televisão; por outro lado, a enorme maioria dos candidatos obteve votação pouco expressiva - por exemplo, 700 candidatos (cerca de $63 \%$ do total) obtiveram menos de mil votos. Nessas circunstâncias, é bem possível que o coeficiente exprima um alto grau de correlação entre uma baixa exposição no HGPE e uma votação pouco significativa, que resultaria simplesmente do fato de haver muitos candidatos que satisfazem a ambas as condições.

Uma tal correlação tem pouco valor do ponto de vista do argumento aqui considerado. Nosso objetivo é verificar se os candidatos que contaram com mais tempo na televisão também obtiveram votações mais expressivas, e não estabelecer uma correlação entre votações inexpressivas e uma fraca presença no HGPE. Assim, calculamos o coeficiente 
de correlação de Pearson em uma amostra mais reduzida, constituída pelos candidatos que obtiveram uma exposição grande, média ou pequena no HGPE, isto é, por aqueles que contaram com pelo menos 5 segundos de tempo médio diário na televisão (a amostra incluiu candidatos situados no intervalo de 5 a 40 segundos por dia). O índice de correlação resultante foi de $0,17(\mathrm{n}=86)$, bem menos expressivo do que o da amostra geral.

Quando projetamos nosso argumento sobre as faixas propostas, constatamos que apenas 12 dos vereadores eleitos tiveram grande ou média exposição no HGPE. Entre os demais, 25 se situaram na faixa que identificamos como de pequeno destaque. É nessa faixa que encontramos a maioria dos vereadores que obtiveram votações expressivas: 5 entre os 10 vereadores que lideraram a votação e 15 entre os 25 mais bem votados; outros 13 vereadores se localizaram na faixa de nenhum destaque.

O conjunto dos dados apresentados sugere que o impacto eleitoral do HGPE sobre as eleições parlamentares é bastante limitado. Naturalmente, é possível identificar evidências dessa influência em um ou outro caso isolado. É o que ocorre, por exemplo, com Édson Santos, candidato que obteve grande destaque nos programas do HGPE (foi o quinto candidato com mais tempo na televisão) e garantiu uma votação considerável (foi o quarto candidato mais votado) e, sobretudo, bem distribuída ao longo de todo o território do município. Essa, porém, é a exceção, e não a regra. O conjunto dos dados apresentados sugere que sua presença nesses programas reflete cálculos cuja lógica é fundamentalmente partidária, antes de eleitoral.

\section{Distribuição do Tempo e Resultado Eleitoral: Uma Perspectiva Intrapartidária}

O terceiro conjunto de dados que analisamos se baseia na distribuição do tempo entre os candidatos no interior dos partidos políticos. Trata-se, em primeiro lugar, de tentar identificar alguns traços básicos das estratégias dos partidos políticos no que concerne à distribuição do tempo entre seus candidatos e, em segundo lugar, de verificar se existe alguma correlação entre a quantidade de tempo obtida por candidato e sua ordem de votação dentro do partido.

Para começar, analisaremos os casos do PFL e do PMDB, dois partidos que dispuseram de uma quantidade razoável de tempo no HGPE e que adotaram estratégias semelhantes na distribuição do tempo entre seus 
candidatos. O PFL contou com um tempo diário médio de 3 minutos e 29 segundos, e teve 65 candidatos a vereador na eleição de 2004, dos quais apenas 1 contou com tempo na televisão; no PMDB, o tempo diário médio foi de 2 minutos e 56 segundos, e os candidatos foram 60, 3 dos quais não obtiveram tempo no HGPE. Em ambos os casos, verifi-

Tabela 6

Tempo Total em Segundos por Partido e Percentagem do Tempo Total

\begin{tabular}{l|c|c}
\hline Partido & Tempo Total do Partido & $\%$ \\
\hline PFL & 7.807 & 14,0 \\
PT & 7.679 & 13,8 \\
PSDB & 6.647 & 11,9 \\
PMDB & 6.513 & 11,7 \\
PP & 3.157 & 5,7 \\
PTB & 2.872 & 5,2 \\
PL & 2.349 & 4,2 \\
PDT & 2.339 & 4,2 \\
PSB & 2.285 & 4,1 \\
PC do B & 1.891 & 3,4 \\
PPS & 1.820 & 3,3 \\
Prona & 1.703 & 3,1 \\
PSL & 1.020 & 1,8 \\
PRP & 978 & 1,8 \\
PSC & 974 & 1,8 \\
PT do B & 831 & 1,5 \\
PSTU & 788 & 1,4 \\
PV & 735 & 1,3 \\
PCO & 651 & 1,2 \\
PMN & 538 & 1,0 \\
PHS & 461 & 0,8 \\
PTN & 436 & 0,8 \\
PRTB & 338 & 0,8 \\
PSDC & 170 & 0,6 \\
PCB & Total & 0,3 \\
PAN & PTC & \\
\hline Fon & & 0.633 \\
\hline
\end{tabular}

Fontes: TSE e HGPE - município do Rio de Janeiro (2004). 
ca-se uma distribuição relativamente equilibrada do tempo entre os candidatos. Grosso modo, podemos identificar dois grupos de candidato: um com pequeno destaque na distribuição do tempo no HGPE e outro com nenhum destaque. Nos dois partidos, o grupo com pequeno destaque respondeu por um pouco menos de um terço do total dos candidatos com acesso à televisão (20 em 64, no PFL, e 17 em 57, no PMDB). Todos os demais candidatos tiveram direito, em média, a pelo menos 5 segundos por programa, o que os situam na faixa de "nenhum destaque $^{\prime \prime 4}$.

Não obstante as estratégias tenham sido semelhantes, os dois partidos se diferenciaram nitidamente em seus desempenhos eleitorais: enquanto o PFL conseguiu eleger 14 vereadores, o PMDB elegeu apenas 6. Todos os vereadores eleitos pelo PMDB se encontram na faixa de pequeno destaque. Desses, o que mais obteve tempo foi Silvio Ferraz, com uma média de 8,3 segundos por dia; e o que menos obteve foi Jefferson Reis, com 5,2 segundos em média. Entre os vereadores eleitos do PFL, todos, com exceção de um - Nadinho de Rio das Pedras, que obteve uma média diária de 3,4 segundos -, se situaram na faixa de pequeno destaque. Dos 20 vereadores da faixa de pequeno destaque do PFL, 13 foram eleitos. Dentro da faixa, o candidato do PFL que obteve mais tempo foi Alexandre Cerruti, com 9,1 segundos por programa; e o

\section{Gráfico 1}

Distribuição dos Candidatos entre as Faixas de Exposição

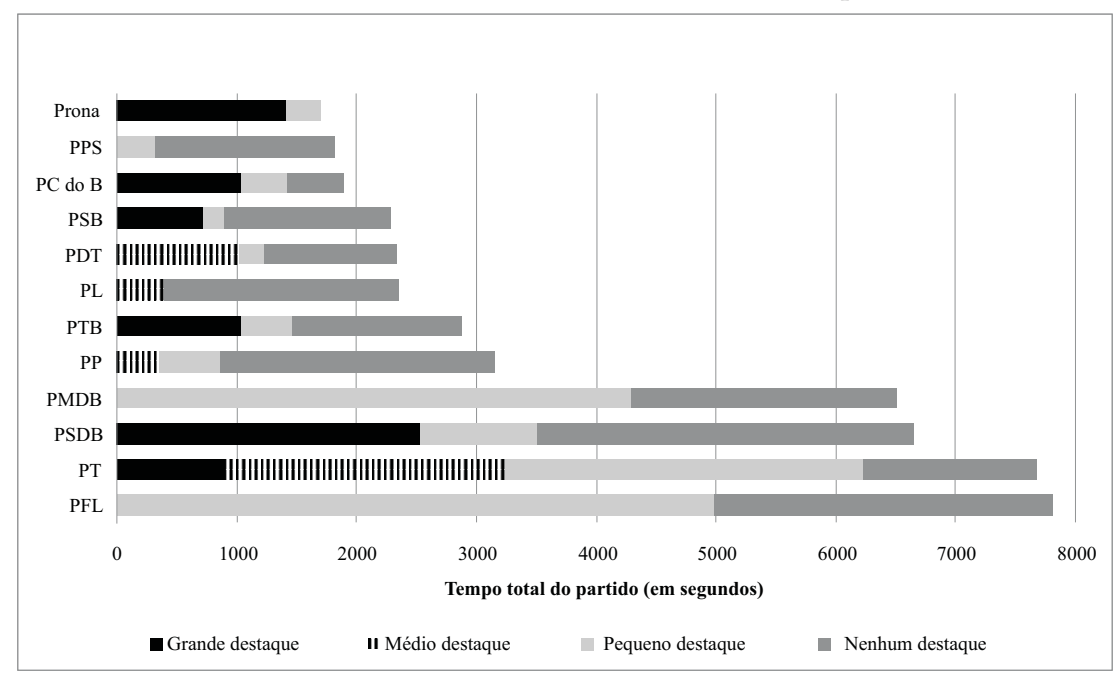

Fonte: HGPE - município do Rio de Janeiro (2004). 
que obteve menos foi Berthaldo Soares, com 5,1 segundos. É importante ter em vista que, dentro dessa faixa, a maioria dos candidatos que não foi eleita obteve votações expressivas. Os 20.552 votos de Jorge Braz, do PMDB, e os 18.620 votos de Cláudio Cavalcanti, do PFL, teriam assegurado sua eleição caso eles tivessem disputado por outras legendas.

Grandes rivais da política nacional na época, bem como nos dias de hoje, o PT e o PSDB recorreram a estratégias eleitorais parecidas. O PT, que contou com 3 minutos e 27 segundos diários, apresentou 63 candidatos, dos quais apenas 1 não obteve espaço no HGPE; no PSDB, com 2 minutos e 59 segundos diários, foram 70 candidatos, dos quais 3 ficaram de fora do HGPE. Ao contrário do que ocorreu com o PMDB e o PFL, a divisão do tempo nos dois partidos aponta para uma forte estratificação. No PT, Édson Santos ocupou sozinho a faixa de grande exposição no HGPE, com uma média de 25,3 segundos; 5 candidatos ocuparam a faixa de média exposição (entre 10 e 14,7 segundos por programa); e 9 ocuparam a faixa de pequena exposição (com um tempo médio aproximado de 9,2 a 9,9 segundos). Entre os demais candidatos, nenhum chegou a atingir um tempo médio de 2 segundos por programa. Sozinho, Édson Santos respondeu por cerca de 11,6\% do tempo total do PT. Somados, os seis candidatos com grande e média exposição obtiveram cerca de $42,2 \%{ }^{5}$. No PSDB, três candidatos obtiveram grande exposição no HGPE: Lucinha (27,6 segundos por programa em média); Luiz Carlos Ramos (22,5 segundos por programa) e Luiz Antônio Guaraná (21,9 segundos por programa). O tempo destinado a Lucinha correspondeu a $14,7 \%$ do total usado pelo partido. Os três candidatos situados na categoria "grande exposição" ocuparam juntos 38\% do tempo total do PSDB. Nenhum candidato obteve média exposição e quatro tiveram pequena exposição, com um tempo médio por programa situado entre 6,7 e 7,4 segundos. Os demais obtiveram exposição inexpressiva. Os resultados obtidos na votação foram igualmente semelhantes. $\mathrm{O}$ PT elegeu três vereadores, e o PSDB quatro. Nos dois partidos, todos os candidatos com grande exposição no HGPE se elegeram. Os demais vereadores eleitos se situam na faixa de exposição imediatamente inferior (dois vereadores com média exposição no PT e uma vereadora com pequena exposição no PSDB).

Os demais partidos contavam com um tempo consideravelmente menor do que os "quatro grandes" da política nacional. Entre os partidos que analisamos, o PTB, com 1 minuto e 17 segundos diários, foi o que 
adotou a estratégia mais radical de distinção na distribuição do tempo no HGPE. Cristiane Brasil, filha do deputado federal Roberto Jefferson (que participou diretamente da campanha da filha no HGPE), líder do partido no Rio de Janeiro na época, obteve uma média de 29,9 segundos por programa no HGPE (a terceira maior exposição entre todos os candidatos nas eleições de 2004 e o correspondente a 36,4\% de todo o tempo usado pelo partido). Dois outros candidatos - Charbel Zaib e Renato Moura - tiveram uma pequena exposição, e os demais receberam uma exposição insignificante. Cristiane Brasil foi eleita (com 13.315 votos), mas o vereador mais votado do partido foi Renato Moura (14.419 votos), cujo tempo médio por programa foi de apenas 5,5 segundos.

No PL (1 minuto e 3 segundos por dia), a candidata Liliam Sá foi a única que desfrutou de tratamento diferenciado: ocupou sozinha a faixa de média exposição. Ela teve direito a 16,6\% do tempo total do partido e, como vimos, foi eleita. Todos os demais candidatos ocuparam a faixa de nenhum destaque. Dois desses candidatos também foram eleitos: a Pastora Márcia Teixeira, que contou com uma média diária de 2,3 segundos, e Adilson Soares, cujo tempo médio diário foi inferior a um segundo.

O PDT também adotou uma política de destaque diferenciada para alguns candidatos, embora de modo menos pronunciado do que o PTB e o PL. Dois candidatos se destacaram na faixa de média exposição: Brizola Neto, com 16,7 segundos, e Pedro Porfírio, com 12,4 segundos por programas em média. Esses números são bastante expressivos quando se considera que o partido contou somente com 51 segundos diários no HGPE. Um candidato ocupou sozinho a faixa da pequena exposição, com 6,2 segundos. Os demais 61 candidatos que tiveram tempo no HGPE obtiveram uma exposição irrisória. Além de Brizola Neto, dois outros candidatos foram eleitos, ambos na faixa da exposição inexpressiva: Sami Jorge teve direito a um tempo médio de 1,9 segundo por programa, e Nereide Portugal obteve apenas 0,4 segundo por dia.

No PP (1 minuto e 25 segundos diários), Wilson Leite Passos, o único candidato da faixa de média exposição, não foi eleito. Dois candidatos ocuparam a faixa de pouco destaque e ambos foram eleitos.

O PPS adotou uma estratégia semelhante à usada pelo PFL e pelo PMDB, dividindo o tempo em duas faixas próximas (pouco e nenhum destaque). Contudo, dado que ele dispunha de muito menos tempo no 
HGPE (49 segundos diários), a faixa superior foi ocupada por apenas um candidato, Stepan Nercessian (eleito).

Aplicamos o coeficiente de Pearson para mensurar a correlação entre número de votos e quantidade de tempo no HGPE entre os candidatos dos quatro grandes partidos: PFL, PMDB, PT e PSDB. Em todos os casos, obtivemos resultados expressivos. No PFL, o coeficiente resultante foi de 0,78 (n=64); no PT, de 0,80 (n= 63); no PMDB, de 0,82 ( $\mathrm{n}=60)$; e no PSDB, de $0,89(n=70)$. Seria essa uma evidência de um tal impacto eleitoral do HPGE que permitiria supor, como o fazem Schmitt, Carneiro e Kuschnir (1999), a existência de uma "lista partidária informal"? Se considerássemos exclusivamente os dados de partidos que, como o PT e o PSDB, adotaram estratégias fortemente estratificadas de distribuição do tempo na televisão, talvez ficássemos tentados a imaginar que sim. Contudo, o fato de encontrarmos resultados semelhantes para o PMDB e o PFL enfraquece essa hipótese, visto que esses partidos adotaram uma abordagem muito mais homogênea na divisão do tempo entre seus candidatos.

Em resumo, quando consideramos os candidatos de um mesmo partido político, parece existir uma correlação positiva entre o tempo atribuído aos candidatos no HGPE e o número de votos que eles obtêm. Contudo, essa correlação parece dizer menos respeito ao destaque obtido por candidato do que à ordem da distribuição do tempo entre eles. A regra funcionou do mesmo modo tanto nos partidos que adotaram estratégias fortemente diferenciadas na distribuição do tempo quanto naqueles que adotaram um formato mais homogêneo. Os candidatos mais votados tendem a estar situados nas faixas mais altas da distribuição de tempo, seja nas faixas de grande e médio destaque, como no PT e no PSDB, seja na faixa de pequeno destaque, como no PFL e no PMDB. Com base nisso, é razoável propor que a distribuição do tempo no HGPE acompanha a correlação de forças dentro dos partidos políticos e que esta, mais do que a distribuição do tempo no HGPE, explica a diferença na votação dos candidatos.

\section{CONCLUSÃO}

Este artigo procurou examinar a hipótese, apresentada por Schmitt, Carneiro e Kuschnir (1999), de que o HGPE constitui um recurso por meio do qual os partidos organizam "listas partidárias informais". Argumentamos que essa proposição pressupõe pelo menos três afir- 
mações: 1) que os partidos distribuem desigualmente seu tempo no HGPE entre os candidatos;2) que o HGPE tem um impacto substantivo sobre o voto em eleições proporcionais; 3 ) que uma distribuição desigual do tempo no HGPE pode se traduzir, portanto, em uma votação diferenciada para candidatos de um mesmo partido.

Nossa análise indicou que os partidos de fato distribuem desigualmente o tempo entre seus candidatos, embora se valham de estratégias muito diferentes para tal. Em alguns casos, um pequeno número de candidatos (ou mesmo apenas um candidato) é grandemente privilegiado em detrimento de todos os demais; em outros, a distinção é menos acentuada, visto que todos os candidatos se situam nas faixas de pouco destaque ou de nenhum destaque.

Por outro lado, a proposição de que o HGPE tem impacto efetivo sobre a votação parece bastante frágil à luz das evidências que examinamos. Para começar, o perfil de distribuição de votos dos candidatos sugere que a maioria deles foi eleita com base em um esforço de campanha local, antes de ser como conseqüência da influência da televisão. A comparação do grau de destaque dos candidatos no HGPE com a votação obtida por eles tampouco traz evidências sólidas do impacto da propaganda política na televisão sobre a campanha para vereador. Chama a atenção o fato de os candidatos mais votados não ocuparem, em sua maioria, as faixas de grande e de médio destaque, mas se concentrarem sobretudo na faixa de pequeno destaque na distribuição do tempo no HGPE.

Em seu conjunto, as evidências nos obrigam a rever - ou pelo menos a modular - a proposição de que a distribuição do tempo no HGPE atende primariamente a uma estratégia eleitoral por parte dos partidos. É bem verdade que o peso do cálculo eleitoral parece maior em alguns partidos do que em outros: maior no caso de partidos como o PT e o PSDB, que adotaram estratégias baseadas em "puxadores de votos", do que em partidos como o PMDB e o PFL, que pulverizaram o tempo entre diversos candidatos de tal modo que nenhum deles chegou sequer a ter um destaque "médio" no HGPE. Ainda assim, mesmo no caso do PT e do PSDB, a explicação sobre o caráter eleitoral da escolha parece ter fôlego curto, pois, a rigor, a estratégia de puxadores de votos não funcionou: para puxar votos, os candidatos teriam de ter obtido uma votação consideravelmente superior ao quociente eleitoral, o que só aconteceu no caso de Lucinha, do PSDB. Contudo, o caráter forte- 
mente concentrado dos votos da candidata sugere que o HGPE desempenhou um papel de pouco relevo em sua votação.

Sugerimos, então, que é preciso mudar o foco da análise sobre as estratégias dos partidos no que concerne à divisão do tempo no HGPE entre seus candidatos. Mais do que refletir uma estratégia eleitoral consistente e unificada dos partidos políticos, a distribuição do tempo entre os candidatos às eleições proporcionais resulta de um arranjo que visa conciliar os interesses das facções e lideranças políticas dos partidos políticos. Garantir a ordem intrapartidária constitui, assim, um objetivo primário da distribuição do tempo entre os candidatos, tanto ou mais do que conquistar os votos do eleitorado.

(Recebido para publicação em julho de 2007) (Versão definitiva em novembro de 2007) 


\section{NOTAS}

1. Cabe observar que o autor usa o conceito de "partidos catch-all" de modo um tanto impreciso para designar partidos sem identidade ideológica claramente delimitada. Tal uso se afasta claramente da definição original dada por Kirchheimer (1969) ao termo, que tem em vista um conjunto bastante preciso de transformações, o qual teve lugar no âmbito de alguns países da Europa Ocidental, em um contexto de expansão do consumo de massa e apagamento das antigas fronteiras entre as classes sociais. Ao contrário de Mainwaring (2001), Kirchheimer não se vale do termo catch-all para sublinhar a oposição entre partidos com sólida identidade ideológica e partidos ideologicamente frouxos, mas sim para destacar a aproximação entre os partidos burgueses e os partidos de massa na disputa pelo crescentemente importante centro político.

2. Essa explicação é pouco satisfatória, visto que Mainwaring não apresenta qualquer explicação para que os políticos brasileiros adotem tal comportamento, o que sugere que a crítica elaborada pelo autor é de cunho fundamentalmente moral. Tal impressão é reforçada diante de afirmações como a que segue: "Dizer que os partidos catchall brasileiros têm um objetivo único é discutível porque os políticos não se orientam por interesses coletivos. A maioria se preocupa antes de qualquer coisa com sua própria carreira política, de modo que é questionável falar da existência de um objetivo coletivo, quanto mais de um objetivo consensual" (2001:217).

3. A importância da base local para esses dois últimos candidatos é tão evidente que se reflete na própria escolha do nome com o qual eles registraram suas candidaturas.

4. É importante deixar claro que estamos lidando com um valor médio, o que pode encobrir algumas diferenças significativas nas estratégias de apresentação dos candidatos. Entre os candidatos que classificamos na categoria "nenhum destaque", alguns efetivamente apareceram muito pouco nos programas; outros apareceram em poucas ocasiões, mas, quando isso ocorreu, contaram com um tempo de exposição razoável.

5. No caso do PT, a ordem de apresentação dos candidatos no programa reproduziu fielmente a hierarquia relativa à divisão do tempo na televisão. Como regra, Édson Santos abria os programas, seguido pelos candidatos da faixa de média exposição. $\mathrm{O}$ último bloco era ocupado pelos candidatos da faixa de exposição pequena ou insignificante. 


\section{REFERÊNCIAS BIBLIOGRÁFICAS}

ALBUQUERQUE, Afonso de. (2005), “Política Partidária e Política Midiática: Substituição ou Coexistência?”. Contemporânea, vol. 3, no 1, pp. 9-37.

AMES, Barry. (2003), Os Entraves da Democracia no Brasil. Rio de Janeiro, Editora FGV.

CARREIRÃO, Yan e KINZO, Maria D’Alva G. (2004), "Partidos Políticos, Preferência Partidária e Decisão Eleitoral no Brasil (1989-2002)". DADOS, vol. 47, no 1, pp. 131-168.

DAALDER, Hans. (2002), "Parties: Denied, Dismissed, or Redundant? A Critique", in J. R. Montero, R. Gunther e J. J. Linz (eds.), Political Parties: Old Concepts and New Challenges. New York/Oxford, Oxford University Press, pp. 39-57.

KIRCHHEIMER, Otto. (1969), "The Transformation of the Western European Party System", in F. S. Burin e K. L. Shell (eds.), Politics, Law, and Social Change: Selected Essays of Otto Kirchheimer. New York/London, Columbia University Press, pp. 346-371.

LIMA, Venício A. de. (1994), “Televisão e Poder: A Hipótese do ‘Cenário de Representação da Política' (CR-P)”. Comunicação E Política, vol. 1, no 1, pp. 5-22.

MAINWARING, Scott. (1995), "Brazil: Weak Parties, Feckless Democracy", in S. Mainwaring e T. R. Scully (eds.), Building Democratic Institutions: Party Systems in Latin America. Stanford, Stanford University Press.

. (2001), Sistemas Partidários em Novas Democracias: O Caso do Brasil. Porto Alegre/Rio de Janeiro, Mercado Aberto/Editora FGV.

MANIN, Bernard. (1995), "As Metamorfoses do Governo Representativo”. Revista Brasileira de Ciências Sociais, no 29, pp. 5-34.

MONTERO, José Ramón e GUNTHER, Richard. (2002), “Introduction: Reviewing and Reassessing Parties", in J. R. Montero, R. Gunther e J. J. Linz (eds.), Political Parties: Old Concepts and New Challenges. New York/Oxford, Oxford University Press, pp. $1-35$.

NICOLAU, Jairo. (1996), Multipartidarismo e Democracia: Um Estudo sobre o Sistema Partidário Brasileiro (1985-94). Rio de Janeiro, Editora FGV.

PEREIRA, Carlos e MUELLER, Bernardo. (2003), "Partidos Fracos na Arena Eleitoral e Partidos Fortes na Arena Legislativa". DADOS, vol. 46, no 4, pp. 735-771.

SAMUELS, David. (1997), "Determinantes do Voto Partidário em Sistemas Eleitorais Centrados no Candidato: Evidências sobre o Brasil". DADOS, vol. 40, no 3, pp. 493-535.

SANTOS, Fabiano. (2002), "Partidos e Comissões no Presidencialismo de Coalizão". DADOS, vol. 45, no 2, pp. 237-264.

SCHMITT, Rogério, CARNEIRO, Leandro Piquet e KUSCHNIR, Karina. (1999), “Estratégias de Campanha no Horário Gratuito de Propaganda Eleitoral em Eleições Proporcionais". DADOS, vol. 42, no 2, pp. 277-301.

WATtenberG, Martin P. (1991), The Rise of Candidate-Centered Politics. Cambridge/ London, Harvard University Press. 


\section{LISTA DE SIGLAS}

PAN - Partido dos Aposentados da Nação

PCB - Partido Comunista Brasileiro

PCO - Partido da Causa Operária

PDT - Partido Democrático Trabalhista

PFL - Partido da Frente Liberal

PHS - Partido Humanista da Solidariedade

PL - Partido Liberal

PMDB - Partido do Movimento Democrático Brasileiro

PMN - Partido da Mobilização Nacional

PP - Partido Progressista

PPS - Partido Popular Socialista

Prona - Partido de Reedificação da Ordem Nacional

PRP - Partido Republicano Progressista

PRTB - Partido Renovador Trabalhista Brasileiro

PSDB - Partido da Social Democracia Brasileira

PSDC - Partido Social Democrático Cristão

PSL - Partido Social Liberal

PSTU - Partido Socialista dos Trabalhadores Unificado

PT - Partido dos Trabalhadores

PTB - Partido Trabalhista Brasileiro

PTC - Partido Trabalhista Cristão

PT do B - Partido Trabalhista do Brasil

PTN - Partido Trabalhista Nacional

PV - Partido Verde 


\section{ABSTRACT \\ The Flip Side of Free Election Advertising: Political Parties, Proportional Elections, and Television}

This article analyzes the impact of Free Television Advertising on proportional elections in Brazil, based on an analysis of the data for the Rio de Janeiro City Council elections in 2004. The article discusses the hypothesis raised by Schmitt, Carneiro, \& Kuschnir that free TV advertising time allows political parties to organize their candidates hierarchically, establishing informal "slates". The study thus links two types of evidence, concerning: 1) the efficacy of free TV time as an instrument for political communication, whereby more TV time tends to translate into more votes for a candidate and 2) the analysis of different strategies adopted by the political parties to split the free advertising time between the candidates.

Key words: political communication; television; Free Televised Election Campaign Advertising; proportional elections; political parties

\section{RÉSUMÉ}

L'Autre Face de l'Horaire Gratuit: Les Partis Politiques et les Élections Proporionnelles à la Télévision

Dans cet article, on examine l'impact de l'Horaire Gratuit de Propagande Électorale (HGPE) sur les élections proportionnelles, à partir de l'analyse des données concernant les élections à Chambre Municipale de Rio de Janeiro en 2004. On y discute l'hypothèse selon laquelle, d'après Schmitt, Carneiro et Kuschnir, le HGPE permet aux partis politiques d'établir une hiérarchie entre ses candidats, en composant des listes "informelles". Pour cela, on considère, de façon articulée, deux types d'évidences concernant: 1) l'efficacité du HGPE comme instrument de communication politique, de façon qu'un temps plus long résulterait tendanciellement par l'obtention de davantage de voix par le candidat; 2) l'analyse des différentes stratégies d'attribution de temps à chaque candidat, adoptées par les partis politiques.

Mots-clé: communication politique; télévision; Horaire Gratuit de Propagande Électorale; élections proportionnelles; partis politiques 